\title{
The Thermal and Structural Analysis of Vertical Stability Coil
}

\author{
Xianewei Wang ${ }^{1}$, Peng Han², Qing $\mathrm{He}^{1}$, Xiulian $\mathrm{Li}^{1}$ \\ 1Jiangsu University of Technology, Changzhou 213001, China. E-mail: 582763914@qq.com, qqaa611@163.com, \\ 936303415@qq.com, \\ 2North Information Control Research Academy Group Co.,Ltd, Nanjing, 211100, China. E-mail: \\ wangxw@jsut.edu.cn
}

The vertical stability coil is a new set of saddle shaped non-superconducting coil designed for the purpose of improving the control capability of plasma vertical movement. To avoid the electromagnetic shielding and enhance the response performance, the vertical stability coil is installed in the inner wall of vacuum vessel. The subsequent disadvantage accompanying the benefit is that the coil is under severe neutron radiation. Besides the neutron radiation the coil will also encounter the Ohmic heat once it is energized. The temperature rising of vertical stability coil is not allowed to beyond the specific threshold to guarantee the reliability of the coil components. Thus, the Ohmic heat and nuclear heat calculation methods are presented and the detail temperature field is analysed by using ANSYS to check whether or not the coil can bear the thermal load. In addition, the thermal load will result in the thermal stress. To verify whether the thermal stress will lead to the structural damage, the thermal-structural coupling analysis is launched and the stress is evaluated based on ASME analytical design. The analysis results will provide guidance for the local structural optimization of vertical stability coil.

Keywords: Vertical stability, Ohmic heat, Nuclear heat, Stress evaluation

\section{Introduction}

To deal with the characteristic of plasma inherently vertical instability, a set of saddle-shaped In-Vessel Coil, namely the Vertical Stability (VS) coil is proposed. In order to improve the response capability, the VS coil is installed between the thermal shielding blanket and vacuum vessel wall. The coil is composed of the upper and lower VS coil, which are connected in series with opposite current $[1,2,3,4,5]$. The upper VS coil with the major diameter of $12.199 \mathrm{~m}$ and tilting down angle of $26.1^{\circ}$ is arranged at the position of $4.905 \mathrm{~m}$ above the fusion device middle plane. The lower VS coil is located at the position of $2.5 \mathrm{~m}$ vertically below the middle plane and the major diameter and tilting down angle are $15.242 \mathrm{~m}$ and $37.8^{\circ}$ respectively. Considering the extremely severe operation circumstance of large dose neutron radiation, high temperature and strong magnetic field. The Stainless Steel Mineral Insulation Conductor (SSMIC) is developed for the coil. The complex SSMIC contains three different layers, they are the outer stainless steel protection layer $316 \mathrm{LN}$, the middle anti-radiation and insulation layer magnesium oxide and the inner water cooled hollow copper tube $[6,7,8,9]$. Besides the conductor components, the coil also contains some affiliated fixing and supporting accessories such as spine, sleeve and clamp. The coil is finally settled at the inner vacuum vessel wall through the numerous toroidal arranged supporting rails as shown in Fig. 1. In view of the fact that the upper VS coil is closer to the plasma, which means it needs to bear more severe neutron radiation compared with the lower VS coil. The upper VS coil is selected in the paper for the sake of conservative analysis.

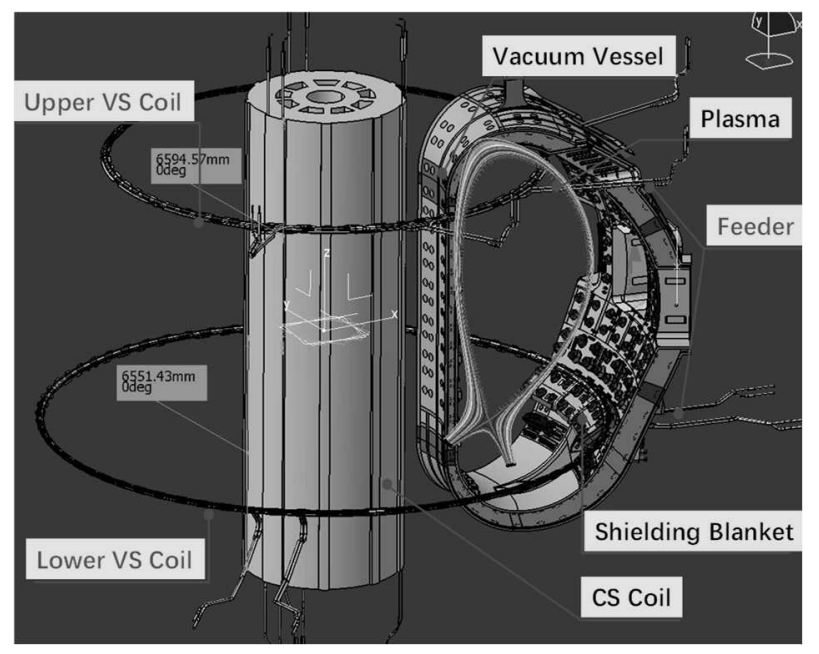

Fig. 1 The geometrical structure of VS coil

\section{The calculation of temperature field}

Based on the engineering design requirement of VS coil, the temperature enhancement caused by thermal load is not allowed to exceed the threshold of $250^{\circ} \mathrm{C}$. The thermal load is mainly originated from neutron radiation, Ohmic heat and radiation from other around components. While the radiation from around 
components can be neglected because of their small temperature difference with VS coil. The purpose of thermal analysis is to obtain the detailed VS coil temperature distribution, which will be used as the thermal boundary for the following thermal-structural coupling analysis. Note that the plasma contains many different operation scenarios, the Deuterium-Tritium (T-D) operation mode is selected in the paper to carry out the steady state thermal analysis. The peak current in VS coil per conductor is $60 \mathrm{kA}$, the generated Ohmic heat can be calculated as shown in equation (1). The nuclear heat can be calculated by using the MCNP code. Since the component of clamp is closest to the plasma. Thus, it has the largest nuclear heat density and the value is about $0.7 \mathrm{MWm}^{-3}$. The nuclear heat decays in the exponential form along the vacuum vessel thickness direction, as shown in formula (2)

$$
\begin{gathered}
q=\frac{\rho I^{2}}{A^{2}}\left[\mathrm{~W} \cdot \mathrm{m}^{-3}\right], \\
q=Q \cdot e^{-r / \lambda}\left[\mathrm{MW} \cdot \mathrm{m}^{-3}\right],
\end{gathered}
$$

Where:

$\rho$ the electrical resistivity of copper conductor at $100^{\circ} \mathrm{C}[\mu \Omega \cdot \mathrm{m}]$,

$I$ the peak current flowing through the copper conductor $[\mathrm{A}]$, $\left[\mathrm{m}^{2}\right]$,

$A$ the cross-sectional area of copper conductor

$Q$ the nuclear heat on the VS coil surface $[\mathrm{MW} \cdot \mathrm{m}-$ 3],

$r$ the distance along the radial direction [m],

$\lambda$ the decay eigenvalue of nuclear heat [m].

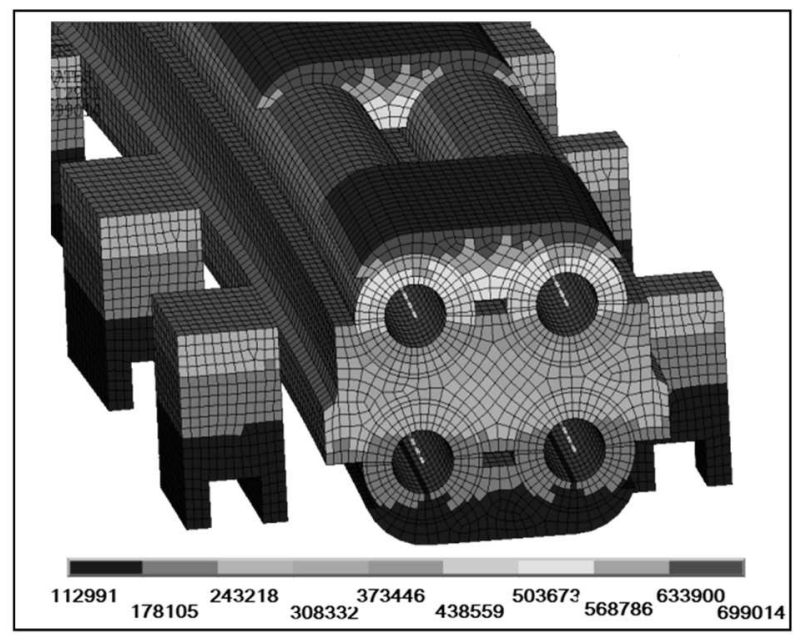

Fig. 2 Nuclear heat distribution on VS coil

During the thermal analysis the Ohmic and nuclear heat are treated as inner source heat to apply on the calculation model. Thus, the heat transfer process mainly refers to heat convection and heat conduction. Since the VS coil is cooled by water, there is heat convection between the copper inner surface and water coolant [10-12]. The heat transfer can be described by the following Newton-cooling equation.

$$
\begin{aligned}
q & =h \cdot\left(t_{1}-t_{2}\right)\left[\mathrm{W} \cdot \mathrm{m}^{-2}\right], \\
N u_{D} & =0.023\left(\frac{V D}{\nu}\right)^{0.8}\left(\frac{\rho \nu c_{p}}{\lambda}\right)^{0.4}[-], \\
h & =N u_{D} \frac{\lambda}{D}\left[\mathrm{~W} \cdot\left(\mathrm{m}^{2} \mathrm{~K}\right)^{-1}\right],
\end{aligned}
$$

Where:

$q$ the heat flux of copper tube inner surface $\left[\mathrm{W} \cdot \mathrm{m}^{-2}\right]$, $h$ the convection coefficient $\left[\mathrm{W} \cdot\left(\mathrm{m}^{2} \cdot \mathrm{K}\right)^{-1}\right]$,

$t_{1}$ the temperature of copper tube inner surface $\left[{ }^{\circ} \mathrm{C}\right]$,

$t_{2}$ the water temperature $\left[{ }^{\circ} \mathrm{C}\right]$,

$N u_{D}$ the Nusselt number [-],

$V$ the water flowing velocity $\left[\mathrm{m} \cdot \mathrm{s}^{-1}\right]$,

$D$ the hydraulic equivalent diameter $[\mathrm{m}]$,

$\nu$ the kinematic viscosity $\left[\mathrm{m}^{2 \cdot} \cdot \mathrm{s}^{-1}\right]$,

$\rho$ the water density $\left[\mathrm{kg} \cdot \mathrm{m}^{-3}\right]$,

$C_{p}$ the constant pressure specific heat $\left[\mathrm{J} \cdot\left(\mathrm{kg} \cdot{ }^{\circ} \mathrm{C}\right)^{-1}\right]$,

$\lambda$ the coefficient of heat conduction $\left[\mathrm{W} \cdot(\mathrm{m} \cdot \mathrm{K})^{-1}\right]$

Tab. 1 Cooling water properties $\left(1.82 \mathrm{MPa}, 114^{\circ} \mathrm{C}\right)$

\begin{tabular}{lll}
\hline Parameters & Value & Unit \\
$\begin{array}{l}\text { Heat conduction coeffi- } \\
\text { cient }\end{array}$ & 0.685 & $\mathrm{~W} \cdot(\mathrm{m} \cdot \mathrm{K})^{-1}$ \\
Specific heat & 4240 & $\mathrm{~J} \cdot(\mathrm{kg} \cdot \mathrm{K})^{-1}$ \\
Density & 947.8 & $\mathrm{~kg} \cdot \mathrm{m}^{-3}$ \\
kinematic viscosity & $2.64 \mathrm{E}-7$ & $\mathrm{~m}^{2} \cdot \mathrm{s}^{-1}$ \\
Velocity & 3 & $\mathrm{~kg} \cdot \mathrm{m}^{-3}$ \\
Inlet/outlet temperature & 102 & ${ }^{\circ} \mathrm{C}$ \\
& 127 & ${ }^{\circ} \mathrm{C}$ \\
\hline
\end{tabular}

If both the Ohmic heat and nuclear heat are treated as inner heat source, the heat conduction can be described as shown in equation (6). To obtain the detailed temperature distribution on VS coil, a representative $40^{\circ}$ model containing feeder is created as shown in Fig. 3. The finite element model is shown in Fig. 4. Since the coil body is connected with other fixed components through welding, brazing or bolting, the bonded contact is defined at the interfaces. And given the fact that the coil supporting rails and feeder supporting brackets are welded at the inner surface of vacuum vessel. The bottom surfaces of the supporting components are set as $100^{\circ} \mathrm{C}$. Based on formula (1) the calculated heat density is $1.02 \times 108 \mathrm{Wm}^{-3}$, which is applied on the copper tube as the volumetric heat. By solving the equations (3)-(5) the calculated coefficient of heat convection is $16693.24 \mathrm{~W} \cdot\left(\mathrm{m}^{2} \cdot \mathrm{K}\right)^{-1}$. Then, the nuclear heat as a position related function (shown in formula (2)) is applied on the coil finite element model. The reference temperature of turn 03L, turn 01, turn 02 , turn 04 and turn $03 \mathrm{R}$ are $100^{\circ} \mathrm{C}, 103^{\circ} \mathrm{C}, 104^{\circ} \mathrm{C}$, $101^{\circ} \mathrm{C}$ and $105^{\circ} \mathrm{C}$ respectively. All the fixation and supporting components use the material of stainless steel 316LN. And the material properties used in the thermal analysis are listed in Table 2. 


$$
c \rho \frac{\partial u}{\partial t}-\left[\frac{\partial}{\partial t}\left(k u_{x}\right)+\frac{\partial}{\partial y}\left(k u_{y}\right)+\frac{\partial}{\partial z}\left(k u_{z}\right)\right]=F(x, y, z, t),
$$

Where:

$C$ the material specific heat $\left[\cdot\left(\mathrm{kg}^{\circ} \mathrm{C}\right)^{-1}\right]$,

$\rho$ the material density $\left[\mathrm{kg} \cdot \mathrm{m}^{-3}\right]$,

$u$ the temperature function related with position and time $\left[{ }^{\circ} \mathrm{C}\right]$,

$u_{x}$ the temperature function in the $x$ direction component $\left[{ }^{\circ} \mathrm{C}\right]$,

$u_{y}$ the temperature function in the $y$ direction component $\left[{ }^{\circ} \mathrm{C}\right]$,

$u_{z}$ the temperature function in the $z$ direction component $\left[{ }^{\circ} \mathrm{C}\right]$,

$F$ the inner heat source $\left[\mathrm{W} \cdot \mathrm{m}^{-3}\right]$

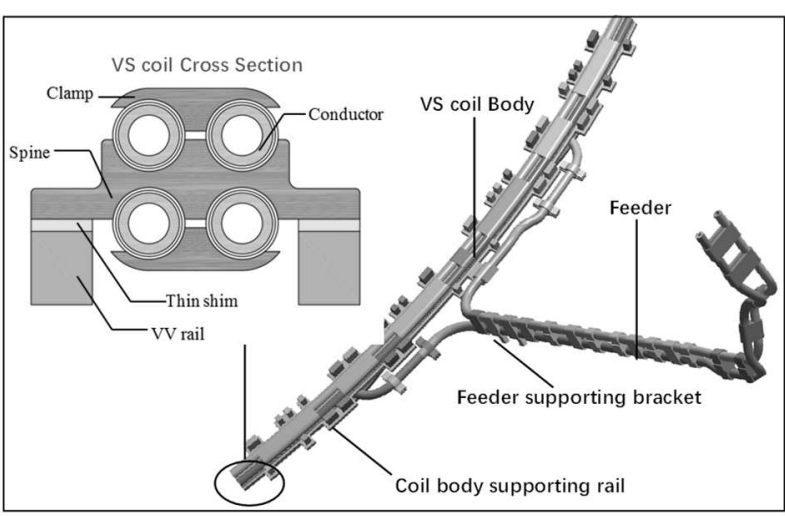

Fig. 3 The $40^{\circ}$ analysis model

Tab. 2 VS coil material properties under different temperatures

\begin{tabular}{|c|c|c|c|c|c|c|}
\hline Parameters & \multicolumn{2}{|c|}{ Stainless steel (316LN) } & \multicolumn{2}{|c|}{ Copper (C10200) } & $\mathrm{MgO}$ & Unit \\
\hline Temperature & 100 & 200 & 100 & 200 & - & ${ }^{\circ} \mathrm{C}$ \\
\hline Density & & 00 & 8903 & 8854 & 2200 & $\mathrm{Kg} \cdot \mathrm{m}^{-3}$ \\
\hline Elastic modulus & $1.92 \mathrm{e} 11$ & $1.83 \mathrm{e} 11$ & $1.14 \mathrm{e} 11$ & $1.10 \mathrm{e} 11$ & $9.6 \mathrm{e} 8$ & $\mathrm{~Pa}$ \\
\hline Poisson's ratio & 0.298 & 0.306 & 0.33 & 0.33 & 0.3 & - \\
\hline $\begin{array}{l}\text { Coefficient of thermal } \\
\text { expansion }\end{array}$ & 16.8 & 17.2 & 17.2 & 17.59 & 12.8 & $10^{-6} \mathrm{~K}^{-1}$ \\
\hline $\begin{array}{l}\text { Coefficient of heat con- } \\
\text { duction }\end{array}$ & 15 & 16.6 & 395 & 388 & 2.36 & $\mathrm{~W} \cdot(\mathrm{m} \cdot \mathrm{K})^{-1}$ \\
\hline Specific heat & 489 & 523 & 394 & 401 & 940 & $\mathrm{~J} \cdot(\mathrm{Kg} \cdot \mathrm{K})^{-1}$ \\
\hline
\end{tabular}

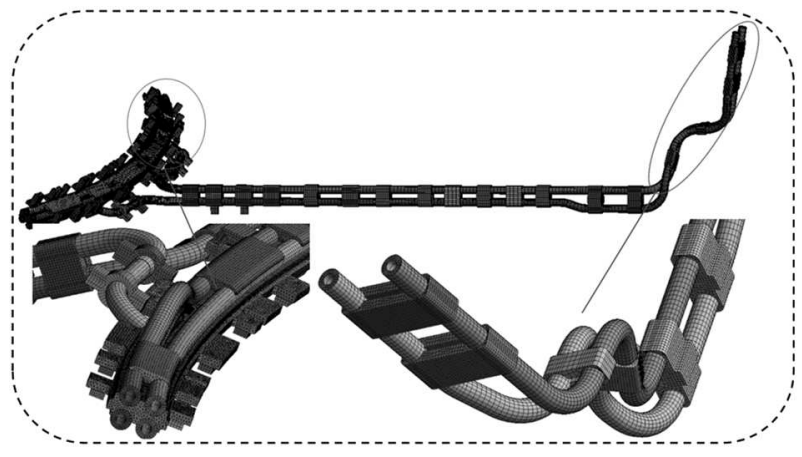

Fig. 4 The $40^{\circ}$ finite element model

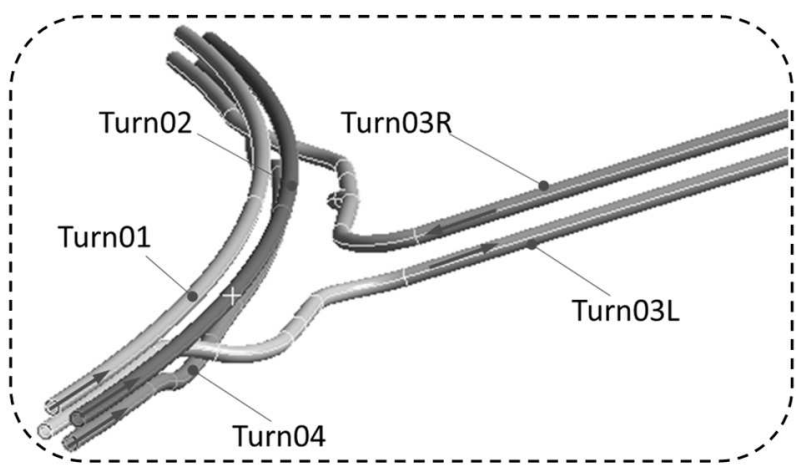

Fig. 5 The current flow of different turns
The steady thermal analysis results of VS coil are shown in Fig. 6-8. The temperature increasement caused by Ohmic heat are shown in Fig. 6-A. The maximum temperature is $111.9^{\circ} \mathrm{C}$, which occurs at the breakout region of leading out feeder jacket shown in Fig. 6-B. The temperature of jacket at this region is a little bit higher than that at the outlet region, which is due to the heat in the breakout region is mainly taken away by the supporting brackets. While for the outlet feeder jacket, not only the supporting brackets but also the lower temperature inlet feeder is helpful to carry the heat from outlet jacket away. The temperature increasement induced by nuclear heat is shown in Fig. 7-A. The highest temperature is $198.3^{\circ} \mathrm{C}$, which occurs at clamp surface facing the plasma side shown in Fig. 7-B. Because it is closest to the high temperature plasma. The result is consistent with the theoretical calculation. The results also indicate the effect of nuclear heat is much more significant than the Ohmic heat. The total temperature rising of VS coil under the combination of Ohmic and nuclear heat is about $104^{\circ} \mathrm{C}$ (shown in Fig. 8). And the local highest temperature is about $205^{\circ} \mathrm{C}$, which is within the temperature threshold of $250^{\circ} \mathrm{C}$. 

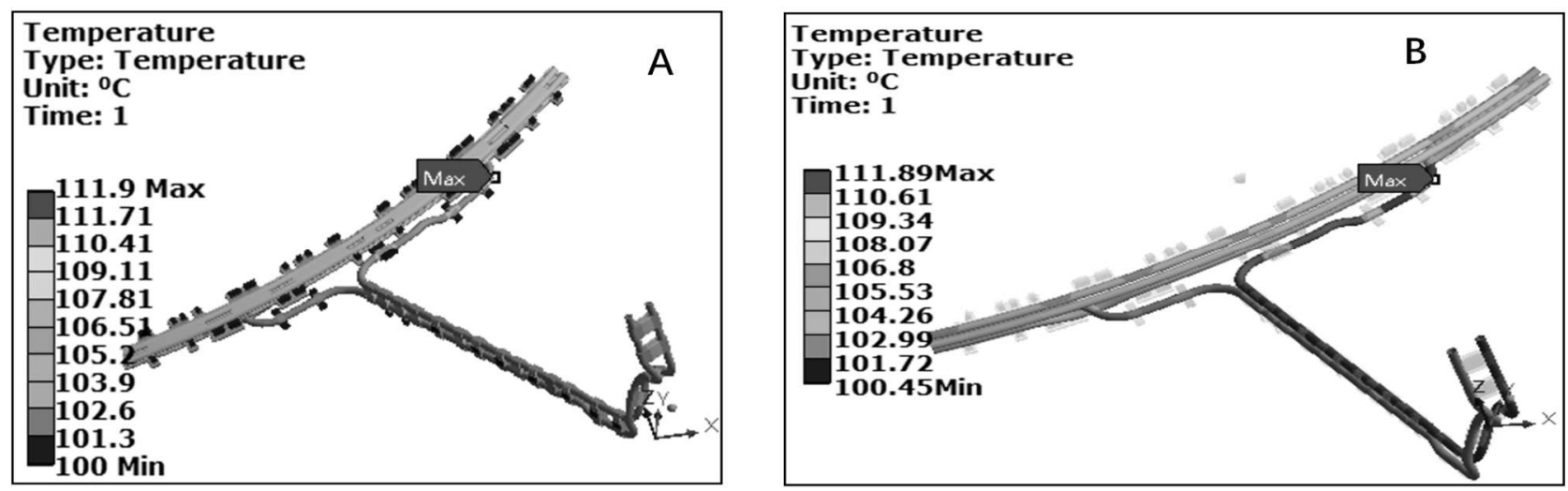

Fig. $\mathbf{6}($ A) The temperature of VS coil under Obmic heat. (B) The temperature of jacket under Obmic beat
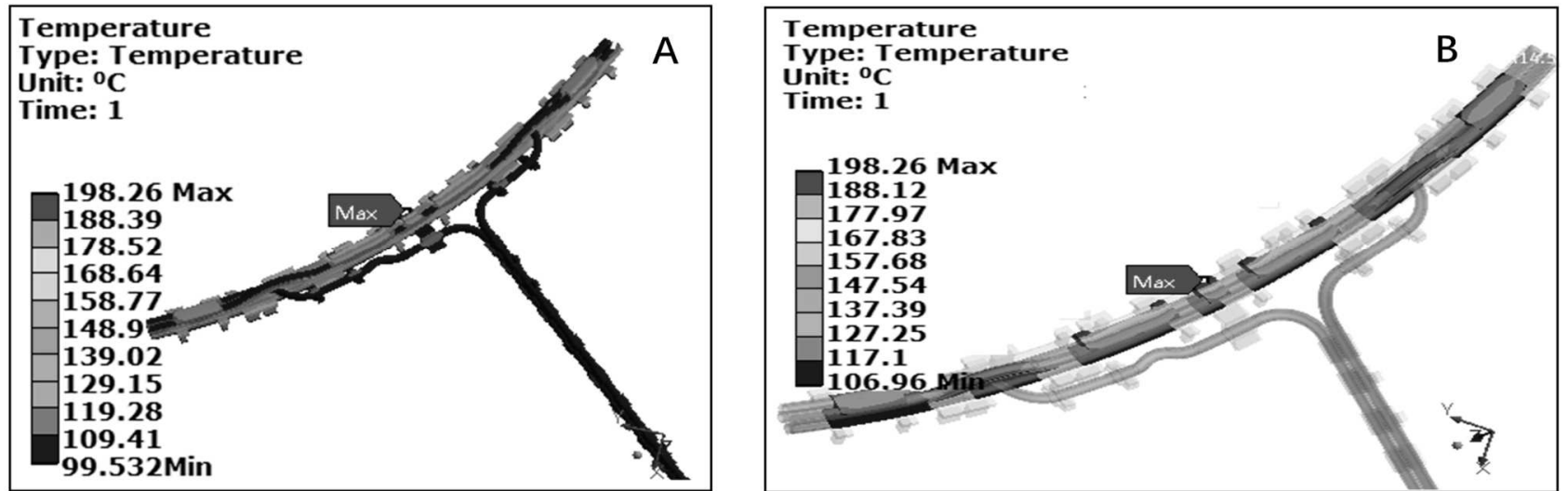

Fig. 7 (A) The temperature of VS coil under nuclear heat. (B) The temperature of clamp under nuclear heat

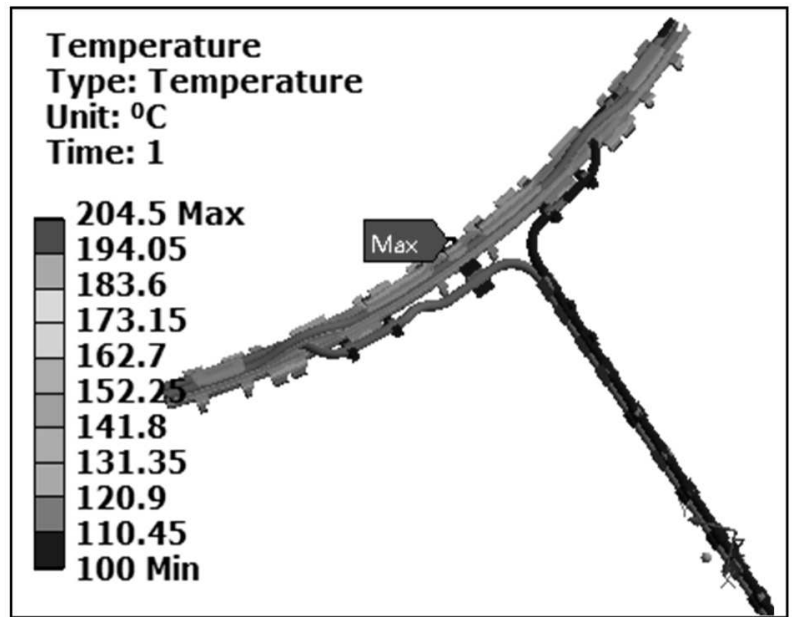

Fig. 8 The temperature of VS coil under Ohmic heat and nuclear beat

\section{The thermal-structural coupling analysis and stress evaluation}

\subsection{The coupling field analysis}

In order to analyse the stress resulted from the temperature field, the thermal-structural coupling analysis [13-15] is carried out by using the same finite element model of thermal analysis. Some small structures such as bolts, fillets and weld are neglected for the convenience of model creation. Due to the complica- ted geometric structure, multi-kinds of meshing technology such as sweep, mapping and multi-zone are adopted and the high-order element is used to improve the calculation accuracy. The total number of elements is 1,540,000 and the node number is up to $9,830,000$. Since the supporting rail is welded to the vacuum vessel. Thus, the fixed restraint is applied on the bottom surface during the analysis. The feeder supporting bracket is connected with the vacuum vessel. But it can move in the feeder length direction to offset the thermal deformation. However, to avoid feeder interfering with other components, the normal displacement and rotation of bracket are restricted. The frictionless restraint is applied on the high and low boundaries to simulate the whole model. The temperature field is input from the result file of thermal analysis. The equivalent stress of VS coil under thermal load are shown in Fig. 9-10. The maximum thermal stress caused by Ohmic heat is about $90.44 \mathrm{MPa}$, which occurs at the break-out jacket. The peak stress induced by nuclear heat is much higher and the value is about $345.9 \mathrm{MPa}$, which occurs at the connection region of supporting rail and spine. The maximum stress of VS coil under the combination of Ohmic and nuclear heat is about $383.4 \mathrm{MPa}$, which also occurs at the connection region of supporting rail and spine. The analysis results indicate the thermal stress in mainly determined by the nuclear heat. 


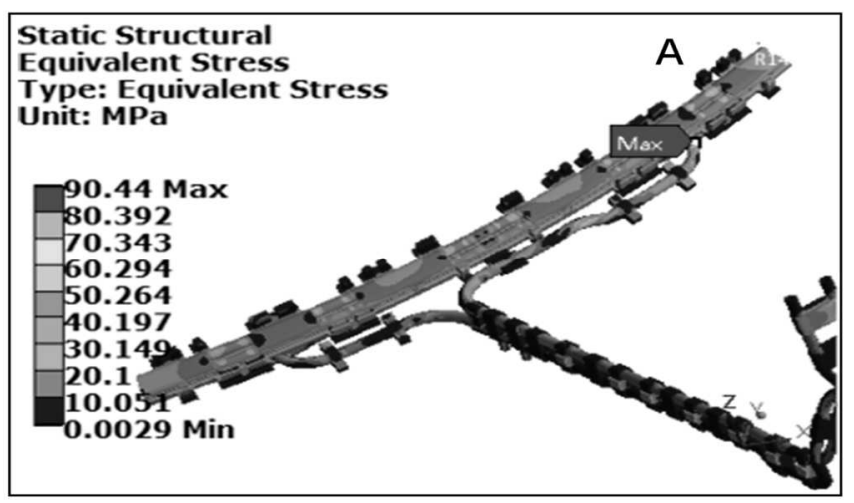

Fig. $9(A)$ The equivalent stress under Ohmic heat.

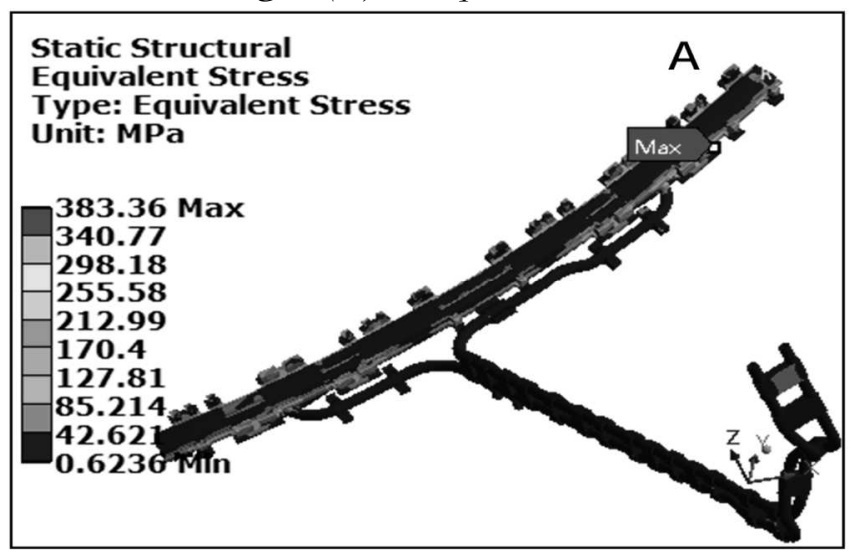

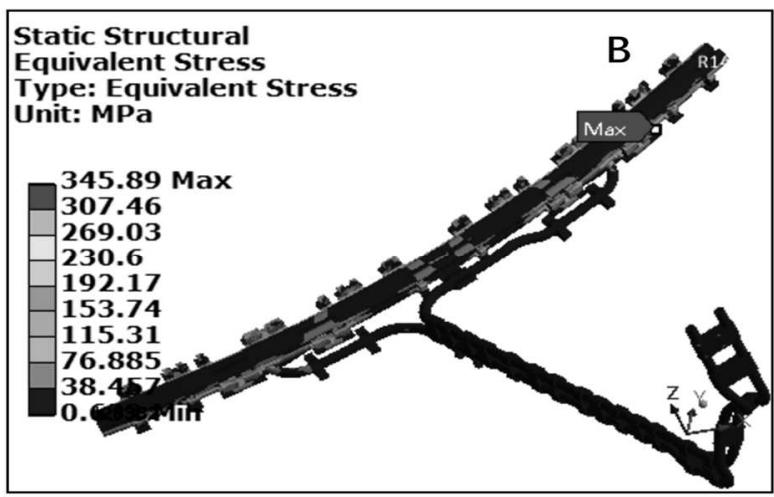

(B) The equivalent stress under nuclear heat

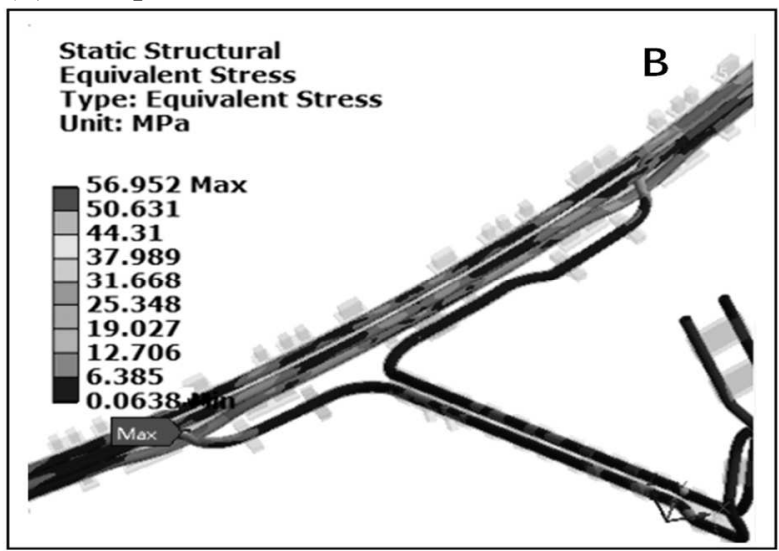

Fig. 10 (A) The equivalent stress under Ohmic heat and nuclear heat. (B) The equivalent stress of copper conductor under Ohmic beat and nuclear heat

\subsection{Stress evaluation based on analytical design}

The key problem of stress evaluation is to classify the stress. There are several different classification methods [15]. Where we adopt the ASME VIII-2 Part 5 criterion. Based on the stress generation reason, action and distribution area, the stress is classified into primary stress, secondary stress and peak stress. The primary stress is further divided into general membrane stress, local membrane stress and bending stress. The different stress is evaluated with different threshold. The specific evaluation principal is listed in Table 3. Where $S_{m}$ is the design stress intensity, which equals to the lesser value of $2 / 3$ yield strength and $1 / 2$ ultimate strength. The stress caused by thermal load belongs to the category of secondary stress. Thus, the maximum stress on the copper tube should be within the threshold of $90 \mathrm{MPa}$. The above thermal-structural coupling analysis shows the maximum thermal stress on the copper conductor is about $57 \mathrm{MPa}$ and is lower than the stress limit. That is to say, the copper tube satisfies the stress evaluation requirement from the perspective of thermal load. For the components using 316LN, the thermal stress induced by Ohmic heat is far smaller than the threshold. However, the thermal stress caused by nuclear heat is beyond the stress limit range of $285 \mathrm{MPa}$ and is up to $342 \mathrm{MPa}$.
In fact, the actual engineering coil model contains fillets, which are helpful to mitigate the local stress concentration.

Tab. 3 The stress evaluation criterion

\begin{tabular}{|c|c|c|c|c|}
\hline \multirow{3}{*}{ Stress type } & \multicolumn{4}{|c|}{ Stress limit $(\mathrm{MPa})$} \\
\hline & \multicolumn{2}{|c|}{ Copper } & \multicolumn{2}{|c|}{ Stainless steel } \\
\hline & $100^{\circ} \mathrm{C}$ & $200^{\circ} \mathrm{C}$ & $100^{\circ} \mathrm{C}$ & $200^{\circ} \mathrm{C}$ \\
\hline $\begin{array}{l}\text { Primary mem- } \\
\text { brane }\end{array}$ & 30 & 28 & 114 & 95 \\
\hline $\begin{array}{l}\text { Local mem- } \\
\text { brane }\end{array}$ & 45 & 56 & 171 & 143 \\
\hline $\begin{array}{l}\text { Membrane } \\
\text { plus bending }\end{array}$ & 45 & 56 & 171 & 143 \\
\hline $\begin{array}{l}\text { Secondary } \\
\text { stress }\end{array}$ & 90 & 84 & 342 & 285 \\
\hline
\end{tabular}

\section{Conclusion}

The Ohmic heat is calculated and applied as volumetric heat on the finite element model to analyse the generated temperature rising. The analysis results indicate the maximum temperature increasement is about $12^{\circ} \mathrm{C}$, which happened at the coil break-out region and the outer layer protection jacket had the highest temperature. The neutron radiation decays along the radial direction. Thus, the nuclear heat is described by using the function related with the radius. Since clamp is the component closest to plasma, it bears the largest dose 
of neutron radiation. And the nuclear heat density is about 0.7 MW per unit volume. The nuclear heat function is also applied on the finite element model as an inner heat source. The thermal analysis shows the temperature rising caused by nuclear heat is about $98^{\circ} \mathrm{C}$, which occurred at the clamp surface of plasma facing side. The result denotes nuclear heat is the key factor affecting the temperature distribution of VS coil. The total temperature rising induced by the Ohmic heat and nuclear heat is about $104^{\circ} \mathrm{C}$, which satisfies the engineering design requirement. The maximum thermal stress resulted from Ohmic heat is about $90 \mathrm{MPa}$. The maximum thermal stress induce by nuclear heat is about $346 \mathrm{MPa}$. The stress evaluation is carried out based on ASME analytical design. The evaluation results indicate Ohmic heat will not lead to the structural damage. While under the severe neutron radiation, the local thermal stress on the coil is beyond the stress threshold. The coil local optimization is needed in the following work. The transient thermal fatigue is ignored in the paper. Because the temperature of vacuum vessel is lower than the VS coil. Therefore, the compressive force due to the different temperature will restrain the expansion of fatigue crack.

\section{Acknowledgment}

This project has been financially supported by the Natural Science Foundation of China (Grant No. 51805230, 51605208).

\section{References}

[1] R. ALBANESE, G. AMBROSINO, M. ARIOLA, ET AL. (2009). ITER vertical stabilization system. In: Fusion Engineering and Design, Vol. 84, No.2-6, pp. 394-397. Elsevier. Netherlands.

[2] C. NEUMEYER, A. BROOKS, L.BRYANT, ET AL. (2011). Design of the ITER in-vessel coil. In: Fusion science and technology, Vol. 60, No. 1, pp. 95-99. AMER. USA.

[3] M. KALISH, P. HEITZENROEDER, A. BROOKS, ET AL. (2011). ITER in-vessel coil design and R\&D. 24th IEEE/NPSS Symposium on Fusion Engineering (SOFE), 2011 June 26-30, Chicago, USA.

[4] XIAO B. J., HUMPHREYS D. A., WALKER M. L. ET AL. (2008). EAST plasma control system. In: Fusion engineering and design, Vol. 83, No. 2-3, pp. 181-187. Elsevier. Netherlands.

[5] XIANEWEI WANG, ZHAOLIANG WANG, FEI XIE, ET AL. (2019). Electromagnetic Analysis of the Updated Fast Control Coil for EAST. In: Manufacturing Technology, Vol. 19, No. 1, pp. 172-176. Engineering Village. USA.
[6] G. KALININ, V. BARABASH, A. CARDELLA, ET AL. (2000). Assessment and selection of materials for ITER in-vessel components. In: Journal of Nuclear Materials, Vol. 283, pp. 10-19. Elsevier. Netherlands.

[7] H. JIN, Y. WU, F. LONG, ET AL. (2013). Investigation and analysis on ITER In-Vessel coils' raw-materials. In: Fusion Engineering and Design, Vol. 88, No. 11, pp. 3028-3032. Elsevier. Netherlands.

[8] LONG FENG, WU YU, DU SHIJUN ET AL. (2013). Manufacture of EAST VS In-Vessel Coil. In: Fusion engineering and design, Vol. 88, No. 12, pp. 3194-3198. ELSEVIER. Netherlands.

[9] E. F. DALY, K. IOKI, A. LOARTE ET AL. (2013). Update on Design of the ITER In-Vessel Coils. In: Fusion Science and Technology, Vol. 64, No. 2, pp. 167-175. Taylor \& Francis. USA

[10] POLLI G. M, MUZZI L, POMPEO N, ET AL. (2012). 1-D Electromagnetic and ThermalHydraulic Analysis of the Superconducting Proposal for the CS Magnets of FAST. In: IEEE Transactions on Applied Superconductivity, Vol. 22, No. 3, pp. 4902704. IEEE-Inst Electrical Electronics Engineers Inc. USA

[11] CHEN ZHAOXI, VULLIEZ KARL, FERLAY FABIEN, ET AL. (2015). Design and optimization of the WEST ICRH antenna front face components based on thermal and hydraulic analysis. In: Fusion Engineering and Design, Vol. 94, pp. 82-89. Elsevier. Netherlands.

[12] LIU LIMIN, ZHANG DALIN, LU QING, ET AL. (2016). Preliminary neutronic and thermal-hydraulic analysis of a 2 MW ThoriumBased Molten Salt Reactor with Solid Fuel. In: Progress in Nuclear Energy, Vol. 86, pp. 1-10. Pergamon-Elsevier Science LTD. England.

[13] YANG HONG, SONG YUNTAO, WANG ZHONGWEI, ET AL. (2014). Thermal stress and relieving method of the ITER lower vertical stabilization coil. In: Fusion Engineering and Design, Vol. 89, No. 2, pp. 109-114. Elsevier. Netherlands.

[14] SONTAMINO, ARKARAPON, PHANITWONG, WIRIYAKORN. (2017). Finite element analysis of counterbore-shaped parts by using sheet-bulk metal forming process. In: Manufacturing Technology, Vol. 17, No. 4, pp. 597-602. Engineering Village. USA.

[15] SESHADRI, R. (1996). Robust Stress-classification of pressure components using the GLOSS and GLOSS R-Node methods. In: Journal of Pressure Vessel Technology, Vol. 118, No. 2, pp. 208-215. ASME. USA 